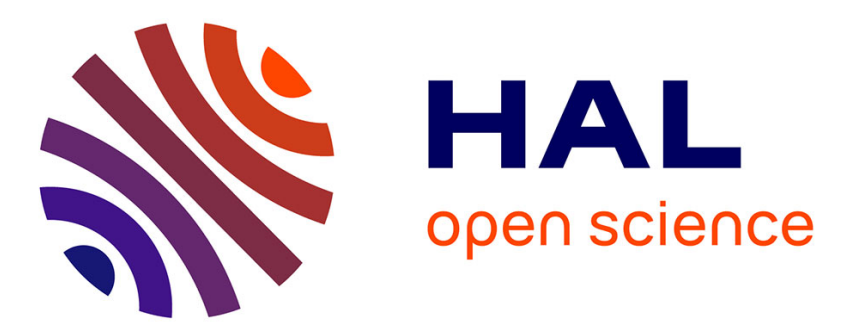

\title{
Graphene attached to glassy carbon surfaces. From simple deposition to redox polymer cathodic generation
}

Jacques Simonet

\section{To cite this version:}

Jacques Simonet. Graphene attached to glassy carbon surfaces. From simple deposition to redox polymer cathodic generation. Electrochemistry Communications, 2013, 36, pp.62-65. 10.1016/j.elecom.2013.09.001 . hal-00915154

\section{HAL Id: hal-00915154 https://hal.science/hal-00915154}

Submitted on 6 Dec 2013

HAL is a multi-disciplinary open access archive for the deposit and dissemination of scientific research documents, whether they are published or not. The documents may come from teaching and research institutions in France or abroad, or from public or private research centers.
L'archive ouverte pluridisciplinaire HAL, est destinée au dépôt et à la diffusion de documents scientifiques de niveau recherche, publiés ou non, émanant des établissements d'enseignement et de recherche français ou étrangers, des laboratoires publics ou privés. 


\title{
Graphene Attached to Glassy Carbon Surfaces. From Simple Deposition to Redox Polymer Cathodic Generation.
}

\author{
Jacques Simonet* \\ Laboratoire MaSCE, UMR 6226, Université de Rennes 1, Campus de Beaulieu, 35042 Rennes \\ Cedex, France.
}

\begin{abstract}
The electrochemical reduction (in aprotic polar solvents) of thin compact graphene layers are mechanically deposited onto flat glassy carbon (GC) surfaces and reduced alone or in the presence of $\alpha, \omega$-dihaloalkanes. These mixed electrolyses implied on one hand graphene moieties considered as redox blocks and/or free radical traps and on the other hand X-R-X as pro-links between graphene islands. Upon electron transfer, $\alpha, \omega$-dihaloalkanes generate reactive transients (e.g. bi-radicals or di-nucleophiles). Additionally, the electrode surface is involved in this process and contributes to create a redox polymer (poly-graphene) really grafted on the electrode that one may imagine highly chemically and electrochemically malleable. This first contribution outlines both the formation and electrochemical capacities of this 3D-electrode.
\end{abstract}

Key-Words: Graphene immobilization; Redox-polymers; Modified electrodes; graphenecarbon interfaces.

Corresponding author: Tel.: +33-23236292; Fax: + 33-23236732

Email: jacques.simonet@univ-rennes1.fr 


\section{Graphical Abstract}

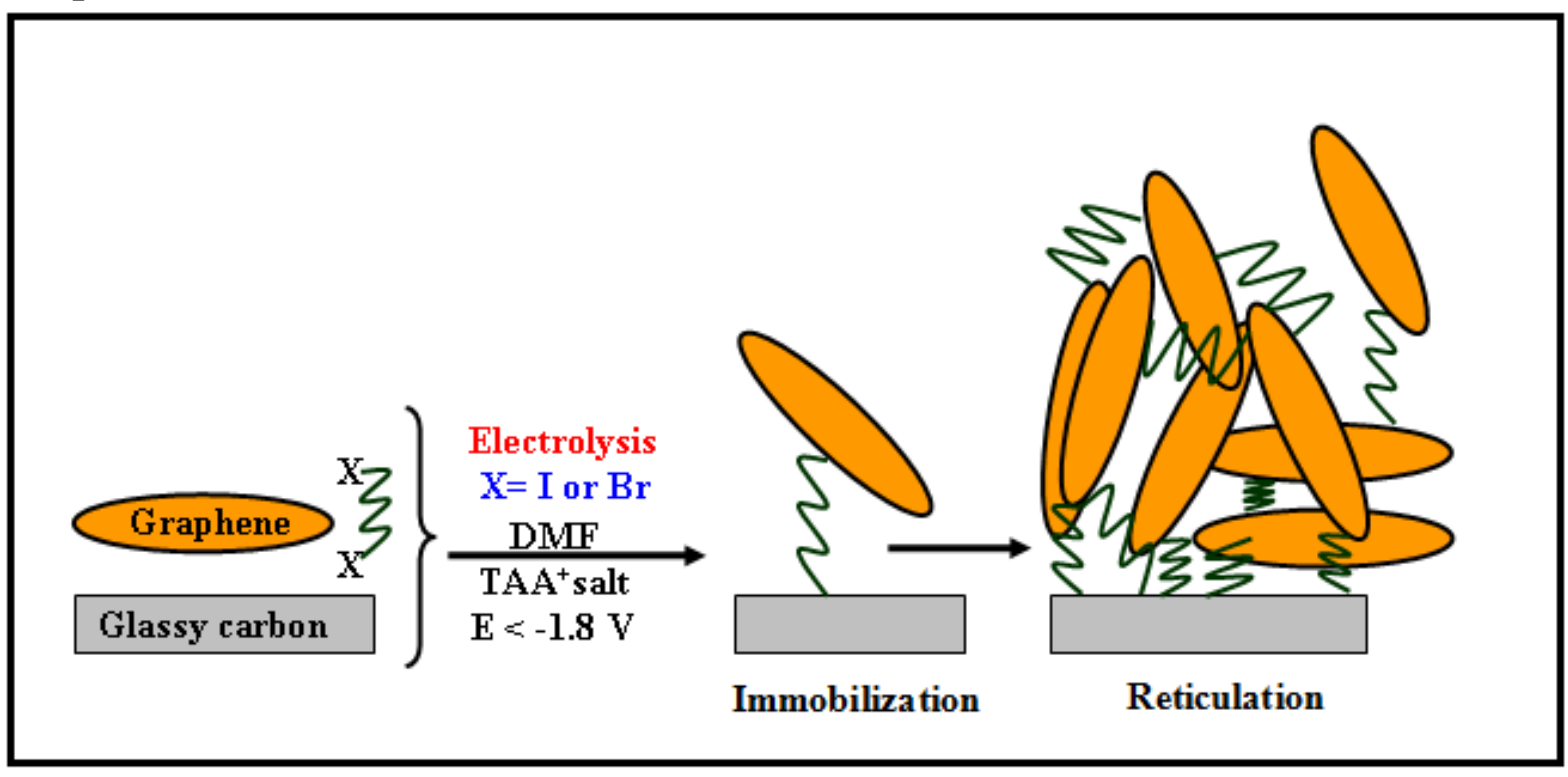

\section{Introduction}

The interest for carbons remains high in electrochemistry. In particular, the use of glassy carbon (GC) as cathode material is general [1] since it is preferred to many metals due to its high hydrogen overpotential. Those electrode materials, when supposed to be non-reactive towards the products issued from electrodes reaction(s), could be considered as almost ideal materials, especially in the field of the cathodic scission of carbon-halogen bonds [2]. The addition of free aryl [3] and alkyl radicals [4] onto glassy carbon permitted one to (re)consider that GC was finally a composite material embedding graphite and fullerenes nano-particles that endow GC with its chemical reactivity.

The intensive research on graphene recently reactivated interest for graphite [5] already developed in electrochemistry, not only for energy storage (lithium batteries) [6] but also for elaborating new reducing materials by potentially controlled ion insertion, especially using tetraalkylammonium salts $\mathrm{TAA}^{+} \mathrm{X}^{-}$that permit one to reach very negative potentials $(<-3 \mathrm{~V}$ vs. $\mathrm{Ag} / \mathrm{AgCl})$ in aprotic polar solvents. With graphite, the progressive ion insertion in the interstices between graphene plans is now a well established process and the overall filling of cracks was found to be strictly dependent on the potential of polarization of graphite [7]. The process leading to almost total exfoliation of graphite by electrochemical insertions of bulky 
$\mathrm{TTA}^{+}$cations have been described [8]. The direct formation of a single graphene plan from a well mastered exfoliation was recently reported $[9,10]$.

If now graphene (two-dimensional $\mathrm{sp}^{2}$ carbon) is specifically considered for being used as GC modifier (despite its remarkable mechanical and electrochemical stability) many difficulties arise principally because its possesses a zero band gap as well as lack of reactivity that limit its potential interest in the field of sensors. Although the possibilities for its immobilization were proposed, principally based on $\pi, \pi$-interactions with basic acceptors the are themselves grafted onto solid (gold) support by conventional means [11], the challenge of easy functionalization of solid surfaces with graphene but without strongly altering the intrinsic properties of this material is still open and positive results in this field are of key importance.

It is developed below a new strategy of fixing graphene onto cathodic materials, exploiting that graphene is a $\pi$-acceptor system. An efficient method is preliminarily presented that permits embedding graphene moieties inside of a network of alkyl chains to yield a kind of redox polymer based on the capability of graphene to be reversibly reduced at potentials $<-1.8 \mathrm{~V}$ in polar aprotic solvents. Moreover, graphene and glassy carbon in their reduced forms may be considered as carbon nucleophiles so the grafting processes should use links possessing at least two electrophilic functions. In this first study, we focused on $\alpha, \omega-$ diiodoalkanes I-( $\left(\mathrm{CH}_{2}\right)_{\mathrm{n}}$-I such as 1,3-diiodopropane (DI3) and 1,4-diioodobutane (DI4) taken in this first submission as target links. As recently reported [4], primary alkyl iodides may quite readily react with charged (or reduced) glassy carbon and one may expect that graphene similarly reacts when potentials $<-1.7 \mathrm{~V}$ are attained. This expectation appears to be the key of the present communication. Second important point is that the compact coverage of GC surface by graphene would provide an efficient 3D immobilization of the material for favouring reaction of dialoalkanes as the linkers. The actual challenge is to obtain a simultaneous electrochemical reactivity with GC surface, graphene, and appropriate dihalides. 
Preliminary results reported hereafter show that these conditions can be fulfilled allowing the formation of redox poly-graphene polymers quite efficiently attached to carbon surfaces.

\section{Experimental section}

Voltammetry was essentially carried out in $0.1 \mathrm{M}$ solutions of tetra- $n$-butylammonium $\left(\mathrm{TBABF}_{4}\right)$ tetrafluoborate, in reagent grade dimethylformamide $(\mathrm{DMF})$. The experiments described in this work needed no special treatment of electrolytic solutions.

Potentials are referred to $\mathrm{Ag} / \mathrm{AgCl} / \mathrm{KCl}_{\text {(sat) }}$ system. Voltammetric and coulometric measurements were performed using three-electrode cells separated with a fritted glass. The electrochemical instrumentation has been previously reported [4].

Glassy carbon (GC) electrodes used as substrates for graphene deposition had geometric area of $7 \mathrm{~mm}^{2}$. All carbon samples were purchased from Tokai Carbon Co (code: GC Rod). Graphene was purchased from XG Sciences as XGnP Graphene Nanoplatelets-Grade C that typically consist of submicron platelets (particle diameter $<2 \mu \mathrm{m}$, with thickness of a few $\mathrm{nm}$ ). The average surface is of the order of $750 \mathrm{~m}^{2} / \mathrm{g}$ and TEM images permit to detect almost transparent platelets. Oxygen content was reported being $<2 \mathrm{wt} \%$ while that of carbon $>98.0$ wt $\%$.

Di-haloalkanes were purchased from Aldrich.

Prior to being modified by deposition of graphene, the electrodes were carefully polished, first with silicon carbide paper (Struers 500) and then with (Struers 1200). Then, graphene was mechanically disposed on the GC surface by strong pressure and rubbed onto on a planar surface (glassy cardboard, or polished agate) until shiny surfaces were obtained. Only after electrolytic treatments, electrodes were sonicated for $5 \mathrm{~min}$ in water and rinsed three times with acetone in order to eliminate the excess of non-grafted graphene.

\section{Results}

Graphene, by itself, is not soluble in current organic solvents such as acetonitrile, dimethylformamide or propylene carbonate. Up to now, the data concerning the cathodic electrochemistry of graphene derived from the in situ reduction of exfoliated graphite oxide [12]. Quite differently, in the present study, a thin layer of graphene was deposited onto the surface of GC electrode. The average thickness of the layer is small, estimated to a few microns. Thus, graphene deposited onto GC displays in $\mathrm{DMF}+\mathrm{TBABF}_{4}$ (Figure 1, curve A1) four main reduction steps (a to d). The first step starting at around $-1.8 \mathrm{~V}$ is reversible and 
probably features one-electron transfers on each graphene moiety although the voltammogram partly looks like the reduction, in the presence of the same electrolyte, of natural graphite crystals immobilized onto GC (compare, in Figure 1, responses B1 -graphite- with B2 graphene- both in the presence of $\mathrm{TBA}^{+}$). The main difference is an easier reduction step for graphite (the arrow on curve B1), that could mean that the first electron transfer onto graphene may start an organization of the material featuring $\pi, \pi$-interactions that produce a pseudo-graphite capable to charge or discharge like graphite. On the basis of a one-electron transfer on each graphene, an average concentration of about $2 \times 10^{-7}$ graphene $\mathrm{cm}^{-2}$ is expected. This seems supporting that graphene participates to a multilayer organization although the interactions relying each graphene moiety to the others in its immediate vicinity are not, for the moment, clarified.

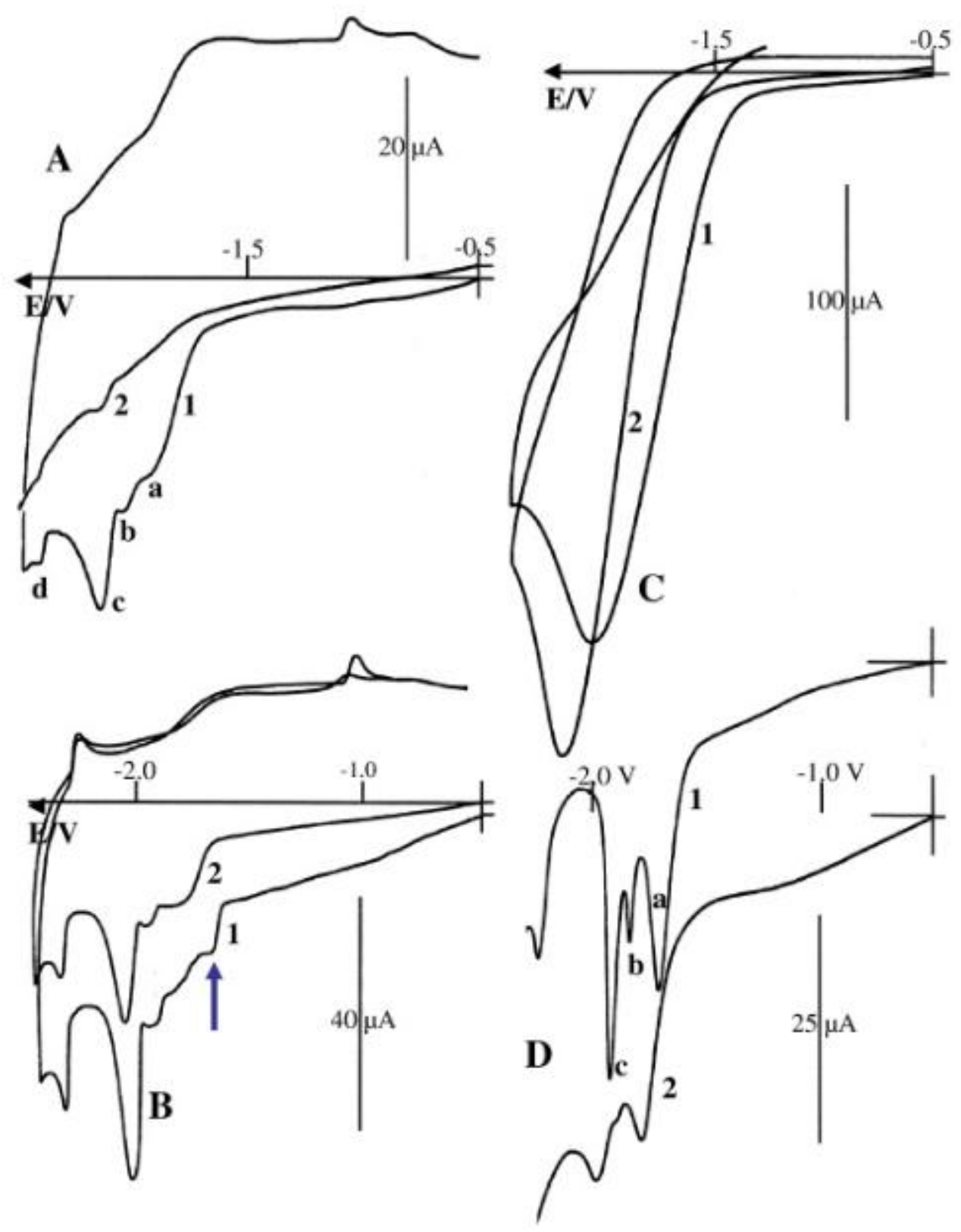


Fig. 1. Cathodic responses of graphene deposited onto carbon (apparent surface area: $7 \mathrm{~mm}^{2}$ ) in $\mathrm{DMF}+\mathrm{TBABF}_{4}$. Scan rate: $50 \mathrm{mV} \mathrm{s}^{-1}$.

A1 and A2: without and with preliminary sonication to voltammetry.

B1: GC electrodes covered with natural graphite and B2: GC/graphene electrode modifified by DI3 (concentration $15 \mathrm{mmol} \mathrm{L}^{-1}$ ) at $-2.2 \mathrm{~V}$ (amount of electricity: $2.310^{-3} \mathrm{C}$ ). Sonication.

C) Electro-reduction of DI4 (concentration: $9.9 \mathrm{mmol} \mathrm{L}^{-1}$ ) at a GC/GR electrode (1) and smooth GC (2).

D) Electrode response (still in DMF/TBABF , forward scans until - 2.5 V) of GC/GR electrodes (in the presence of DB3 (1) and DB4 (2), concentrations of $15 \mathrm{mmol} \mathrm{L}^{-1}$ ) Modifications are obtained after 5 recurrent scans between -0.5 and $-2.6 \mathrm{~V}$.

If now this graphene multilayer is submitted, before any reduction, to sonication (Figure 1, A2), the deposited graphene is readily eliminated from the surface restoring a bare GC surface.

When the reduction is achieved in the presence of a di-haloakane, one observes a fundamental change. Thus, still in Figure 1, curve C, mixed reduction of graphene/DI4 (the later used as an electro-active linker) carried out at $-1.7 \mathrm{~V}$, quite probably through a catalytic process of DI4 activated by deposited graphene. The resulting GC electrode is sonicated for a few minutes and it can be realized that the similarity between A1 and D is striking despite the introduction of butyl links permitting the attachment of graphene onto glassy carbon. Four reduction steps (a to d) are obtained within the potential range $-1.8 \mathrm{~V}$ and $-2.2 \mathrm{~V}$, that is very similar to those already displayed with graphene alone (curve A).

From this point, potentiostatic immobilizations of graphene in the presence of several $\alpha, \omega$ diiodoalcanes alones or in mixture could be achieved in the presence of several salts such as tetraethyl, tetra- $n$-hexyl and tetra- $n$-octylammonium salts. Typically, with diiodoalkanes (concentration about $15 \mathrm{mmol} \mathrm{L}^{-1}$ ), the embedment of graphene seems to be achieved under the conditions given in Figure 2, A and B, with DI4 and DI5. After a sonication, typical I/V curves of the modified surface were obtained supporting the modification as compared with those exhibited in Figure 1, A1 and D. 


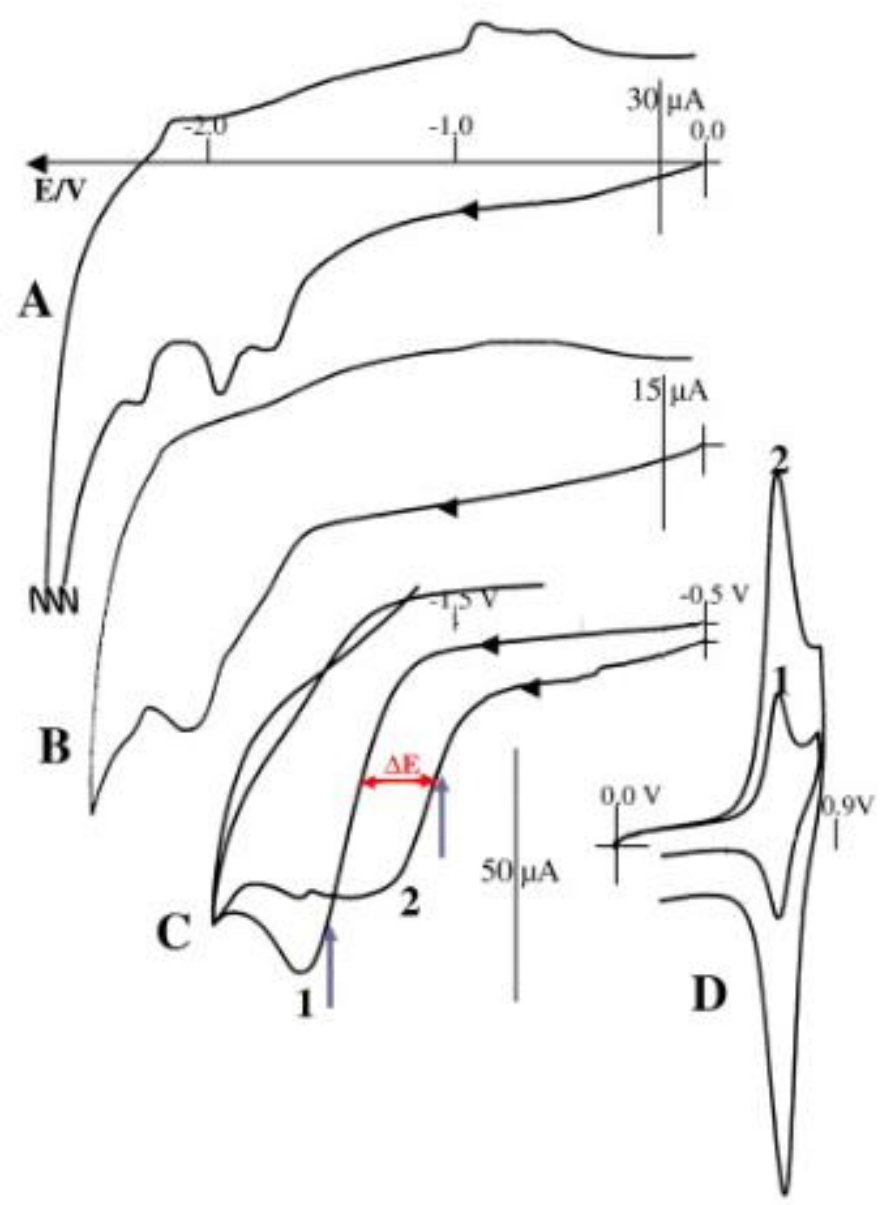

Fig. 2. Charge of GC/GR electrodes in the presence of alkyl iodides. For all presented curves scan rate: $50 \mathrm{mV} \mathrm{s}^{-1}$. Electrolyte: $\mathrm{DMF}+\mathrm{TBABF}_{4}$.

A) In the presence of DI5 (concentration: $1.5 \times 10^{-2} \mathrm{~mol} \mathrm{~L}^{-1}$ ). Applied potential: $-1.8 \mathrm{~V}$. Total charge: $1.610^{-2} \mathrm{C}$.

B) In the presence of DI4. Applied potential: -1.7 V. Charge: $7.3 \times 10^{-2} \mathrm{C}$.

C) Reduction of $\mathrm{Fc}-\left(\mathrm{CH}_{2}\right)_{4}-\mathrm{I}$ (concentration $1.2 \times 10^{-2} \mathrm{~mol} \mathrm{~L}^{-1}$ ) at a smooth GC electrode

(1) and at GC/graphene electrode (2) followed by potentials holds (arrows) of 1 min each.

D) Resulting balance of ferrocene grafting at those surfaces.

Furthermore, it was checked that graphene/GC electrode and the one resulting from the attachment of graphene onto GC do not yield any slowing down of the electron transfer (reduction of $\pi$-acceptors like 1,4-diacetylbenzene or chloranil in the same solvent) and the diffusion of species through the modifying layers.

For the moment, the attachment process that concomitantly implies interaction of GC and of graphene pieces with di-electrophiles I-R-I is certainly complex since the carbon pieces present at the vicinity of the electrode are not necessarily at the same potential and stay through a different surrounding. One may suppose, however, that the potentials of electrolysis 
$<-1.8 \mathrm{~V}$ should globally favour the charge of GC and of graphene therefore orienting the process to $\mathrm{S}_{\mathrm{N}} 2$ type reactions with a di-electrophiles such DI3. On the contrary, when graphene layer is doped with Pd and Au nanoparticles, the reduction of DI3 is strongly shifted to less negative potentials $(\approx-1.5 \mathrm{~V})$ that may suppose attachments could occur via free alkyl radicals. This important point is not totally resolved for the moment. Scheme 1 gathers the elements that could explain the GC modification. It was arbitrary chosen to privilege $\mathrm{S}_{\mathrm{N}} 2$ pathways: $\alpha, \beta$, and $\gamma$ correspond to nucleophilic displacements by electro-generated carbanions implying first GC and then graphene layer, while a global building and swelling of the layer is presented below.
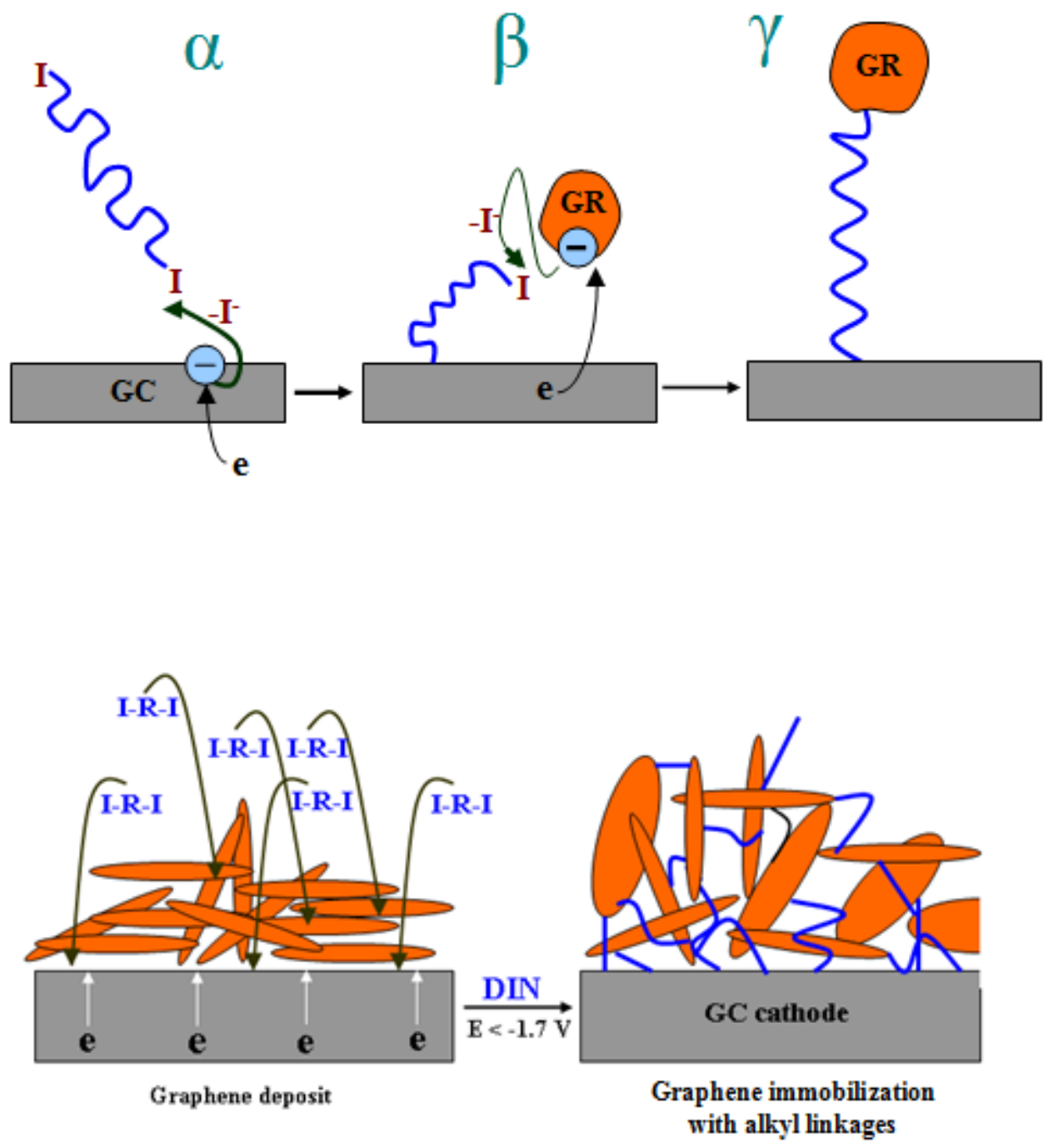

Scheme 1. Proposal for general process considered at $\mathrm{E}<-1.8 \mathrm{~V}$ and based on the probable occurrence of $S_{N} 2$ reactions in the attachment of graphene at GC.

In order to check this, the grafting of a chemically marked 1-iodoalkane at GC surface and at graphene was achieved (Figure 2, C and D). Thus, attempts concerning especially ferrocene- $\left(\mathrm{CH}_{2}\right)_{4}$-I have been achieved and compared. At bare GC, RIs (curve 1) are known 
to be cathodically reduced and alkyl group $\mathrm{R}$ grafted at doped carbon when $\mathrm{E}<-1.7 \mathrm{~V}$. On the contrary, at GC/graphene surface, the reduction wave (curve 2) is efficiently shifted toward less cathodic potentials $(\Delta \mathrm{E} \approx+0.3 \mathrm{~V}$, curve 2$)$ and global ferrocene concentration was then estimated from the anodic oxidation of the resulting surfaces (obtained via potential holds). The redox response obtained with GC/graphene is huge $\left(3.3 \times 10^{-8} \mathrm{~mol} \mathrm{~cm} \mathrm{~cm}^{-2}\right)$ and is significantly higher than those obtained at a simple GC electrode.

\section{Conclusion}

Quite unexpectedly, graphene species can be deposited and then immobilized onto glassy carbon surfaces in the course of mixed electrolyses that imply both GC, graphene nanoplatelets and $\alpha, \omega$-di-haloalkanes that play the fundamental role of links between the GC surface itself and a graphene layer first mechanically deposited on the surface. Under electron transfer activation, dihaloalkanes (here essentially diiodoalkanes) play the role of an anchor at the GC hooking graphene species conveniently disposed at the surface. The conditions described in this first report are particularly simple, and the resulting layer looks as a new kind of redox polymer apparently well anchored to the surface. There is not any definitive proposal on the chemical pattern permitting the formation of such 3D graphene polymers and the process should strongly depend on applied potential (radical vs. $S_{N} 2$ ). The amounts of electricity injected in the course of their formation appear to modify the reactivity of graphenes incorporated in the solid bulk (e.g. by increasing the density of poly-alkane linkage). Moreover, these polyaromatic structures could induce catalytic processes and additionally act as a free radical trap which would accordingly allow the development of other ways for surface modification. Therefore, such poly-graphene coverages will appear quite certainly in the future as attractive and useful materials.

\section{References}

1] R. L. McCreery, Chem. Rev., 108 (2008) 2646.

[2] D. G. Peters, in: H. Lund, O. Hammerich (Eds.), Organic Electrochemistry, M.M. Dekker, New York, Basel, (2001) p. 341.

[3] D. Bélanger, J. Pinson, Chem. Soc. Rev., 40 (2011) 3995.

[4] V. Jouikov, J. Simonet, Langmuir, 28 (2012) 931. 
[5] K. S. Novoselov, A. K. Geim, S. V. Morozov, D. Jiang, Y. Zhang, S. V. Dubonos, I. V. Grigorieva, A. A. Firsov, Science, 306 (2004) 666.

[6] P. Bernier, S. Lefrant, Le carbone dans tous ses états, Gordon and Breach Science Publishers, Amsterdam, (1997), and references cited.

[7] J. O. Besenhard, Carbon, 14 (1976) 111.

[8] J. Simonet, H. Lund, J. Electroanal. Chem., 75 (1977) 719.

[9] W. Sirisaksoontorn, A. A. Adenuga, V. T. Remcho, M. M. Lerner, J. Am. Chem. Soc., 133 (2011) 12438.

[10] Y. L. Zhong, T. M. Swager, J. Am. Chem. Soc., 134 (2012) 17896.

[11] X. Shen, Y. Liu, Y. Pang, W. Yao, Electrochem. Comm., 30 (2013) 13.

[12] S.-J. Li, Y. Xing, G.-F. Wang, Microchim. Acta, 176 (2012) 163.

[13] H. S. Toh, A. Ambrosi, C. K. Chua, M. Pumera, J. Phys. Chem. C, 115 (2011) 17647.

\section{Figure Captions}

\section{Figure 1}

Cathodic responses of graphene deposited onto carbon (apparent surface area: $7 \mathrm{~mm}^{2}$ ) in $\mathrm{DMF}+\mathrm{TBABF}_{4}$. Scan rate: $50 \mathrm{mV} \mathrm{s}^{-1}$.

$\mathrm{A} 1$ and $\mathrm{A} 2$ : without and with sonication.

B1 and B2) GC electrodes covered with natural graphite and graphene, respectively.

C) Electro-reduction of DI4 (concentration: $9.9 \mathrm{mmol} \mathrm{L}^{-1}$ ) at a GC/GR electrode (1) and smooth GC (2).

D) Electrode response (still in DMF / $\mathrm{TBABF}_{4}$ ) after sonication of $\mathrm{C}$ ) after a hold of 1 min at $-1.7 \mathrm{~V}$.

\section{$\underline{\text { Figure } 2}$}

Charge of GC/GR electrodes in the presence of alkyl iodides. For all presented scans: rate: 50 $\mathrm{mV} \mathrm{s}^{-1}$. Electrolyte: DMF + $\mathrm{TBABF}_{4}$.

A) In the presence of DI5 (concentration: $1.5 \times 10^{-2} \mathrm{~mol} \mathrm{~L}^{-1}$ ). Applied potential: $-1.8 \mathrm{~V}$. Total charge: $1.610^{-2} \mathrm{C}$.

B) In the presence of DI4. Applied potential: $-1.7 \mathrm{~V}$. Charge: $7.3 \times 10^{-2} \mathrm{C}$.

C) Reduction of Fc- $\left(\mathrm{CH}_{2}\right)_{4}$-I (concentration $1.2 \times 10^{-2} \mathrm{~mol} \mathrm{~L}^{-1}$ ) at a smooth GC electrode (1) and at GC/Graphene electrode (2) followed by potentials holds (arrows) of 1 min. each. 
D) Resulting balance of ferrocene grafting at those surfaces. 